\title{
Characterization of a hepatitis $C$ virus genotype 1 divergent isolate from an HIV-1 coinfected individual in Germany assigned to a new subtype 10
}

Bo Wang ${ }^{1 \dagger}$, Luise Krüger ${ }^{1 \dagger}$, Patrycja Machnowska ${ }^{2+}$, Amare Eshetu $^{2 \dagger}$, Barbara Gunsenheimer-Bartmeyer ${ }^{3}$, Viviane Bremer ${ }^{3}$, Andrea Hauser ${ }^{2}$, Norbert Bannert ${ }^{2,4 \dagger}$ and C.-Thomas Bock ${ }^{1,5^{*}+}$ (i)

\begin{abstract}
Background: HCV exhibits a high genetic diversity and is classified into 7 genotypes which are further divided into 86 confirmed subtypes. However, there are multiple isolates with unassigned subtypes. We aimed to amplify and characterize the full-length genome sequence of an HCV genotype 1 (HCV-1) divergent isolate (DE/17-0414) in Germany.

Methods: The HCV infection was detected in an HIV-1-positive German female within an HCV/HIV-coinfection study using a commercially available antigen-antibody HCV ELISA kit and confirmed by an in-house quantitative real-time RTPCR assay. Preliminary genotyping was done by sequencing and phylogenetic analysis on partial NS5B region. The fulllength genome sequence was determined by consensus RT-PCR assays. Resistance-associated substitutions (RASs) were analyzed using the web-based tool Geno2pheno $[\mathrm{HCV}$.

Results: Partial NS5B region of the isolate DE/17-0414 showed more than 95\% identity to 73-08460349-1 I and HCV_Fr_ 003 from France and QC316 from Canada. Full-length genome analysis of the DE/17-0414 strain showed 91.8\% identity to QC316 but less than 79.6\% to other HCV-1 strains. Phylogenetic analyses demonstrated that DE/17-0414, 7308460349-1 I, HCV_Fr_003, and QC316 formed a separate subcluster within HCV-1. DE/17-0414 had a distinct 3 amino acids insertion at the $\mathrm{N}$-terminal of hypervariable region 1 (HVR1) within viral envelope glycoprotein 2 (E2) and several potential antiviral RASs among the NS3 and NS5A genes.
\end{abstract}

Conclusions: We identified and analyzed an HCV-1 divergent isolate derived from an HIV-1 coinfected individual in Germany, which will be assigned to a new HCV-subtype 10. Our understanding of the origin and transmission dynamics of this new subtype 10 requires further assessments from patients worldwide.

Keywords: Hepatitis C virus, HIV-1, HCV genotype 1 subtypes, Full-length genome, HVR1, RASs

\footnotetext{
* Correspondence: bockc@rki.de

Bo Wang, Luise Krüger, Patrycja Machnowska and Amare Eshetu are contributed equally to this article.

Norbert Bannert and C.-Thomas Bock are contributed equally and thus shared last authorship.

'Division of Viral Gastroenteritis, Hepatitis Pathogens and Enteroviruses, Department of Infectious Diseases, Robert Koch Institute, 13353 Berlin, Germany

${ }^{5}$ Institute of Tropical Medicine, University of Tübingen, 72076 Tübingen,

Germany

Full list of author information is available at the end of the article
}

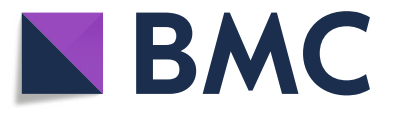

(c) The Author(s). 2019 Open Access This article is distributed under the terms of the Creative Commons Attribution 4.0 International License (http://creativecommons.org/licenses/by/4.0/), which permits unrestricted use, distribution, and reproduction in any medium, provided you give appropriate credit to the original author(s) and the source, provide a link to the Creative Commons license, and indicate if changes were made. The Creative Commons Public Domain Dedication waiver (http://creativecommons.org/publicdomain/zero/1.0/) applies to the data made available in this article, unless otherwise stated. 


\section{Main text}

Hepatitis $\mathrm{C}$ virus (HCV) causes both acute and chronic hepatitis. According to the World Health Organization (WHO), in 2015 an estimated number of 71 million people have been chronically HCV-infected globally [1] Among these, approximately 4 to 5 million individuals are coinfected with HIV [2]. HCV/HIV-coinfections are of major public health concern, as HIV-coinfection is associated with sometimes more serious progression of HCV-infection [2]. Since 2011, direct-acting antivirals (DAAs) for various genotypes of $\mathrm{HCV}$ are available for standard-of-care treatment. However, there is a controversial discussion whether HIV-coinfection is associated with worse response to DAA-based therapy against chronic hepatitis $\mathrm{C}$ in real life than HCV-monoinfected patients $[3,4]$ and the occurrence of potential $\mathrm{HCV}$ resistance-associated substitutions (RASs) is correlated with treatment failure [5]. Therefore, detection of HIV/ $\mathrm{HCV}$-coinfection and monitoring of potential $\mathrm{HCV}$ RASs is of clinical importance [6]. HCV is a positive-strand RNA virus with a $9.7 \mathrm{~kb}$ single-stranded, messenger-sense RNA genome. HCV exhibits a high genetic diversity; there are 7 genotypes, further sub-divided into 86 confirmed subtypes according to the 10th International Committee on Taxonomy of Viruses (ICTV) report on the taxonomy of the family Flaviviridae [7]. Nonetheless, a number of HCV strains are phylogenetically divergent from previously described sequences, thus can only be classified into genotypes but without subtype assignment [8]. Globally, HCV genotype 1 (HCV-1) is dominant (46.2\%) and different genotype/ subtype prevalence evolves and correlates to epidemiological factors [9]. In Germany, a recent study reported that HCV-1a (35.9\%) and HCV-1b (30.6\%) are the most prevalent subtypes, followed by HCV-3 (20.6\%) [10].

In this work, we aimed to amplify and characterize the full-length genome sequence of a $\mathrm{HCV}-1$ divergent strain (DE/17-0414) from an HIV-1 coinfected individual from Germany. According to the "Protection against Infection Act” (IfSG; $\$$ 7) diagnostic laboratories in Germany report new HIV infections anonymously to the Robert Koch Institute (RKI). Approximately $60 \%$ of the reports are submitted together with a dried serum spot (DSS) sample prepared from residual blood of the diagnosis. Antibodies and viral RNAs are isolated from these DSS and are used for sentinel studies (according IfSG \$13) [11]. Within a sentinel study established at the RKI, HIV/HCV coinfections are analyzed. This includes partial sequencing for the determination of the $\mathrm{HCV}$ genotype. HCV-infection was serologically identified using the Monolisa HCV Ag/ Ab ULTRA V2 kit (Bio-Rad, Marnes-la-Coquette, France). Viral RNA from DSS was extracted by the automated Nuclisens EasyMag platform (bioMerieux, Capronne, France) following the manufacturer's instructions. HCV viral load was measured by an in-house quantitative RT-PCR assay targeting the $5^{\prime}$ noncoding region (Table 1 ). Preliminary HCV genotyping was done by a consensus nested RT-PCR assay targeting a 674 base pair fragment in the NS5B region corresponding to nt position 7962 to 8636 of $\mathrm{H77}$ reference strain. After cDNA synthesis using the Transcriptor first-strand cDNA synthesis kit (Roche Diagnostics, Mannheim, Germany), the complete viral genome was amplified using KAPA HiFi HotStart ReadyMix PCR kit (Kapa Biosystems, Boston, USA) with HCV-1 degenerate and DE/17-0414 specific primers (Table 1). The 5' and 3' sequences were determined using $5^{\prime}$ and $3^{\prime}$ rapid amplification of cDNA ends (Roche Diagnostics, Mannheim, Germany). HCV amplicons were sequenced with the BigDye Terminator version 3.1 cycle sequencing kit (Applied Biosystems, California, USA) in both directions. The sequencing chromatograms were checked for overlapping multicolor peaks. Whole-genome sequence was assembled using Geneious software version 10.0.5 (Biomatters, Auckland, New Zealand) [12]. Sequence identity comparisons were performed using the BLASTn search engine (https://blast.ncbi.nlm.nih.gov). Phylogenetic analyses were completed using the Neighbor-Joining method with maximum composite likelihood nucleotide distance between coding regions and complete deletion option in MEGA software version 7 [13], Bootstrapping was performed with 1000 replicates. To identify possible recombination, identity plot and bootscan analyses of full-length sequences were performed in the SimPlot software program version 3.5.1 with a sliding window size of $300 \mathrm{nt}$ and a step size of $15 \mathrm{nt}$ increment [14]. Potential RASs analysis among NS3, NS5A, and NS5B regions were conducted by Geno2pheno ${ }_{[\mathrm{HCV}]}-\mathrm{a}$ web-based interpretation system [15]. Relative numbering of nucleotide (nt), amino acid (aa), insertions and deletions used the HCV reference isolate H77 (GenBank accession number AF009606) [16].

A 63-year-old German heterosexual female, diagnosed with HIV-1 in 2017, was serologically positive for antigen/ antibody combination HCV test. Viral load was $1.6 \times 10^{6}$ $\mathrm{IU} / \mathrm{ml}$ of DSS specimen. Preliminary sequence analysis based on partial NS5B sequences demonstrated that DE/ 17-0414 has an identity of $96.3 \%$ to the isolate QC316 (GenBank accession number KJ439779) from a Canadian immigrant with an origin in Cameroon [17]. It also shows high identities of 95.7 and $95.3 \%$ to isolates $73-$ 08460349-1 1 (GenBank accession number KC960818) and HCV_Fr_003 from France (GenBank accession number GU049346), respectively [18]. However, DE/17-0414 showed less than $83.6 \%$ identity to other $\mathrm{HCV}-1$ strains. Phylogenetic analysis of representative $\mathrm{HCV}-1$ to $\mathrm{HCV}-7$ members of partial NS5B region suggested that DE/170414 belonged to $\mathrm{HCV}-1$ forming an independent sub-cluster with HCV_Fr_003, 73-08460349-11, and 
Table 1 Primers used for HCV quantification, genotyping and DE/17-0414 genome amplification

\begin{tabular}{|c|c|c|c|}
\hline Primer $^{a}$ & Sequence $\left(5^{\prime}-3^{\prime}\right)$ & Location $^{\mathrm{b}}$ & Reference \\
\hline \multicolumn{4}{|c|}{ Real-time RT-PCR assay for HCV quantification } \\
\hline HCV-238_f & GAGGAACTACTGTCTTCACG & $49-68$ & This study \\
\hline HCV-239_r & TCGCAAGCACCCTATCAG & $310-293$ & \\
\hline HCV-240_f & TCGCAAGCACCCTATCAG & $76-94$ & \\
\hline HCV-235_r & AGTACCACAAGGCCTTTCG & $290-272$ & \\
\hline \multicolumn{4}{|c|}{ Heminested RT-PCR assay for HCV genotyping } \\
\hline HCV-271_f & ACCACATCMRSTCCGTGTGG & $7951-7970$ & This study \\
\hline HCV-272_f & $\begin{array}{l}\text { TCCGTGTGGRARGACYT } \\
\text { SCTRGA }\end{array}$ & 7962-7984 & \\
\hline HCV-305_f & CTCCGTMTGGGAGGACTTGC & $7961-7980$ & \\
\hline HCV-275_r & CTSGTCATAGCYTCCGTGAA & $8635-8616$ & \\
\hline \multicolumn{4}{|c|}{ Heminested RT-PCR assays for DE/17-0414 genome amplification } \\
\hline HCV-235_r & AGTACCACAAGGCCTITCG & $290-272$ & This study \\
\hline HCV-239_r & $\begin{array}{l}\text { TCGCAAGCACCCTAT } \\
\text { CAG }\end{array}$ & $310-293$ & \\
\hline HCV-365_f & $\begin{array}{l}\text { GGCGTTAGTATGAGTG } \\
\text { TTGTGC }\end{array}$ & $87-108$ & (Lu et al., 2014) \\
\hline HCV-366_r & $\begin{array}{l}\text { TCCCTGAAGAGTTGCGT } \\
\text { ATTCC }\end{array}$ & 939-918 & \\
\hline HCV-367_r & $\begin{array}{l}\text { AGAAAGAGCAACCGGG } \\
\text { AAGATT }\end{array}$ & $864-843$ & \\
\hline HCV-368_f & $\begin{array}{l}\text { TCTATCTTCCTTCTTGCC } \\
\text { ATCCTG }\end{array}$ & $864-887$ & \\
\hline HCV-369_f & $\begin{array}{l}\text { AGGGATTTACCATGTCA } \\
\text { CCAATGA }\end{array}$ & $935-958$ & \\
\hline HCV-370_r & $\begin{array}{l}\text { TCAAAGTCAGTAAGAG } \\
\text { GTCGACAG }\end{array}$ & $1747-1724$ & \\
\hline HCV-371_f & $\begin{array}{l}\text { CCCGGTGCATGGTAG } \\
\text { ACTAC }\end{array}$ & $2164-2183$ & \\
\hline HCV-372_r & $\begin{array}{l}\text { CTCCACCCTCCGTTG } \\
\text { GTTAG }\end{array}$ & $3421-3492$ & \\
\hline HCV-373_r & $\begin{array}{l}\text { CCGTTGGTTAGGGAG } \\
\text { TCAGC }\end{array}$ & 3412-3393 & \\
\hline HCV-374_f & $\begin{array}{l}\text { ACATTCTTGGCTACGT } \\
\text { GCTGTA }\end{array}$ & $3552-3573$ & \\
\hline HCV-375_f & $\begin{array}{l}\text { CCCCATTATCCAGATGT } \\
\text { ACACCAA }\end{array}$ & $3635-3658$ & \\
\hline HCV-387_r & $\begin{array}{l}\text { TCTGGACTTCTCCCTCC } \\
\text { ACC }\end{array}$ & $3531-3512$ & This study \\
\hline HCV-388_f & $\begin{array}{l}\text { GCCGCATCCAAACATTG } \\
\text { AGG }\end{array}$ & $4421-4440$ & \\
\hline HCV-389_f & $\begin{array}{l}\text { CGGCAAAGCTATCCCCC } \\
\text { TAG }\end{array}$ & 4478-4497 & \\
\hline HCV-390_r & $\begin{array}{l}\text { CCCGCCTGTTITGTCT } \\
\text { GAGA }\end{array}$ & $5089-5070$ & \\
\hline HCV-391_f & $\begin{array}{l}\text { GCATCCAAAGAGGCTG } \\
\text { AGGT }\end{array}$ & $5565-5584$ & \\
\hline HCV-392_f & CATCCCTGCTGTCCCAACTT & $5588-5607$ & \\
\hline HCV-393_r & TTATGTCAGCTCCGCATGGG & $6456-6437$ & \\
\hline HCV-394_f & GACGCCGACCTCATAGAAGC & $7017-7036$ & \\
\hline
\end{tabular}

Table 1 Primers used for HCV quantification, genotyping and DE/17-0414 genome amplification (Continued)

\begin{tabular}{|c|c|c|c|}
\hline Primer $^{a}$ & Sequence $\left(5^{\prime}-3^{\prime}\right)$ & Location $^{\mathrm{b}}$ & Reference \\
\hline HCV-395_r & TGGCGTAACAAGGAGTTGCT & $7708-7689$ & \\
\hline HCV-396_r & ATGGGCAGCTTGTTCTCCTC & $7678-7659$ & \\
\hline HCV-360_f & $\begin{array}{l}\text { CTCACCTGCTATCTC } \\
\text { AAGGCAA }\end{array}$ & $8487-8508$ & \\
\hline HCV-361_f & $\begin{array}{l}\text { GTTATCTGTGAGAGTAG } \\
\text { CGGGG }\end{array}$ & $8574-8595$ & \\
\hline
\end{tabular}

${ }^{a}$ Forward primer designation end with _f; reverse primer designations end with_r

${ }^{\mathrm{b}}$ Numbering is according to the HCV prototype strain of H77 (GenBank Acc. No. AF009606)

QC316 (Fig. 1a). For a more comprehensive analysis of viruses belonging to the cluster, the full-length genome sequence of DE/17-0414 was amplified and sequenced. The complete genome of DE/17-0414 consisted of 9359 nt excluding the polypyrimidine tract, with a $\mathrm{G}+\mathrm{C}$ content of $57.9 \%$ harboring the $10 \mathrm{HCV}$ prospective genomic regions described in Table 2. The complete genome sequence of DE/17-0414 has been deposited in GenBank under the accession number MH885469. DE/17-0414 had the highest identity with the QC316 (91.8\%) and less than 79.6\% with any other HCV strain. Phylogenetic reconstructions based on the whole-genome sequences of HCV-1 strains showed that DE/17-0414 and QC316 formed to a separate subcluster within HCV-1 (Fig. 1b). Identity plot and bootscan analyses reflected no evidence for recombination between different $\mathrm{HCV}$ genotypes or $\mathrm{HCV}-1$ subtypes (Fig. 2a and b). Intriguingly, a unique insertion of three aa (Q-S-R) was found at the N-terminal of hypervariable region 1 (HVR1) within viral envelope protein 2 (E2) (Fig. 3). In addition, several HCV-1 potential DAAs RASs including $36 \mathrm{~L}, 170 \mathrm{~V}$ (NS3 region) and $28 \mathrm{M}, 31 \mathrm{M}, 93 \mathrm{H}$ (NS5A region), were detected in DE/17-0414 (Table 3).

The assignment of $\mathrm{HCV}$ into subtypes and genotypes is based on isolates that differ by $15-25 \%$ and by $\geq 30 \%$, respectively, over their complete coding region sequence [8]. Both DE/17-0414 and QC316 exhibited close to $20 \%$ identity to other known $\mathrm{HCV}$ sequences. According to the ICTV criteria required for a new HCV genotype or subtype assignment which are: (1) one or more complete coding region sequence(s); (2) a distinct phylogenetic group from previously described sequences; (3) at least three epidemiologically unlinked isolates and (4) exclusion of intergenotypic or intersubtypic recombination [8]. The sequences from a total of 4 epidemiologically unlinked isolates that show more than 95\% nucleotide identity have been identified for which the complete genome sequence is available for two of these and the 


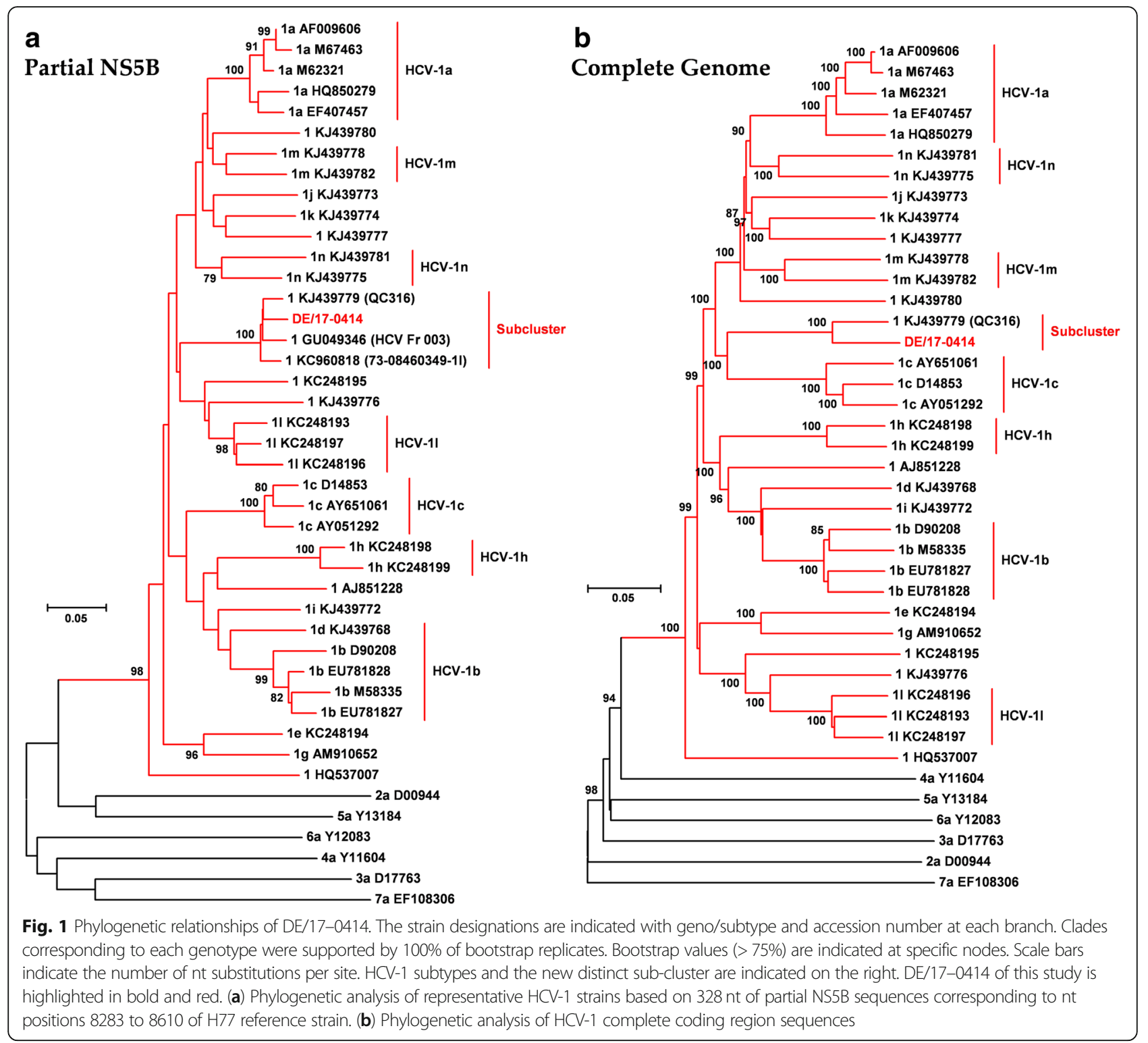

Table 2 Genomic regions of DE/-17-0414

\begin{tabular}{lll}
\hline Genomic region & NA numbering & AA numbering \\
\hline 5' UTR & $1-283$ & NA $^{a}$ \\
Core & $284-856$ & $1-191$ \\
E1 & $857-1432$ & $192-473$ \\
E2 & $1433-2530$ & $474-749$ \\
p7 & $2531-2719$ & $750-812$ \\
NS2 & $2720-3370$ & $813-1029$ \\
NS3 & $3371-5263$ & $1030-1660$ \\
NS4A & $5264-5525$ & $1661-1714$ \\
NS4B & $5526-6208$ & $1715-1975$ \\
NS5A & $6209-7552$ & $1976-2423$ \\
NS5B & $7553-9328$ & $2424-3014$ \\
3' UTR & $9329-9359$ & NA \\
\hline
\end{tabular}

${ }^{\mathrm{a} N A}$ for not applicable partial NS5B sequence for the remaining two. Thus, this meets the criteria for the assignment of a new HCV subtype 10. Subsequently, both DE/17-0414 and QC316 regarded as HCV-1o reference sequences.

The main observed genotypes/subtypes in Germany are $\mathrm{HCV}-1 \mathrm{a}, 1 \mathrm{~b}$ and 3 [10]. In contrast, genetic diversity and distribution of other genotypes/subtypes are poorly documented. However, it is known that shifts or relative frequencies of $\mathrm{HCV}$ subtypes occurred in the last decades and the approval of DAAs for HCV-treatment is an additional factor, which will probably influence the subtype distribution [19]. Therefore, the knowledge on the genetic diversity of $\mathrm{HCV}$ is not only of epidemiological but also clinical significance. The core protein and envelope 


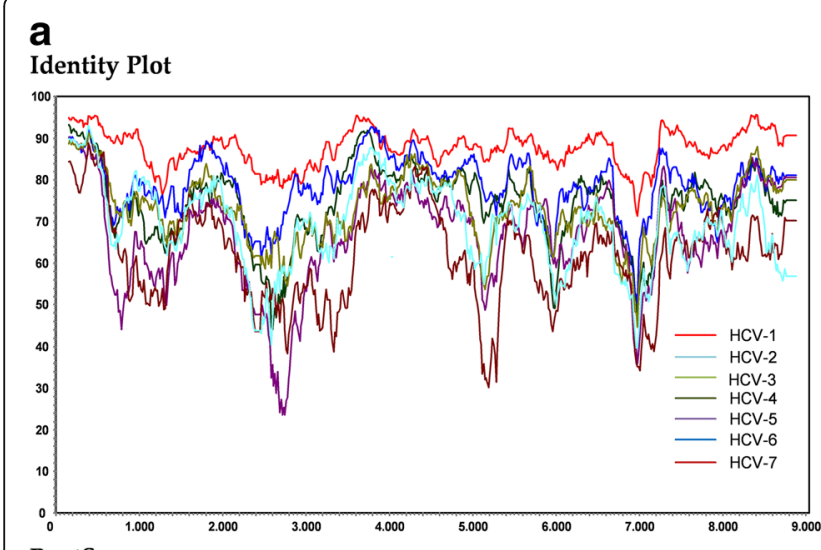

b

Identity Plot
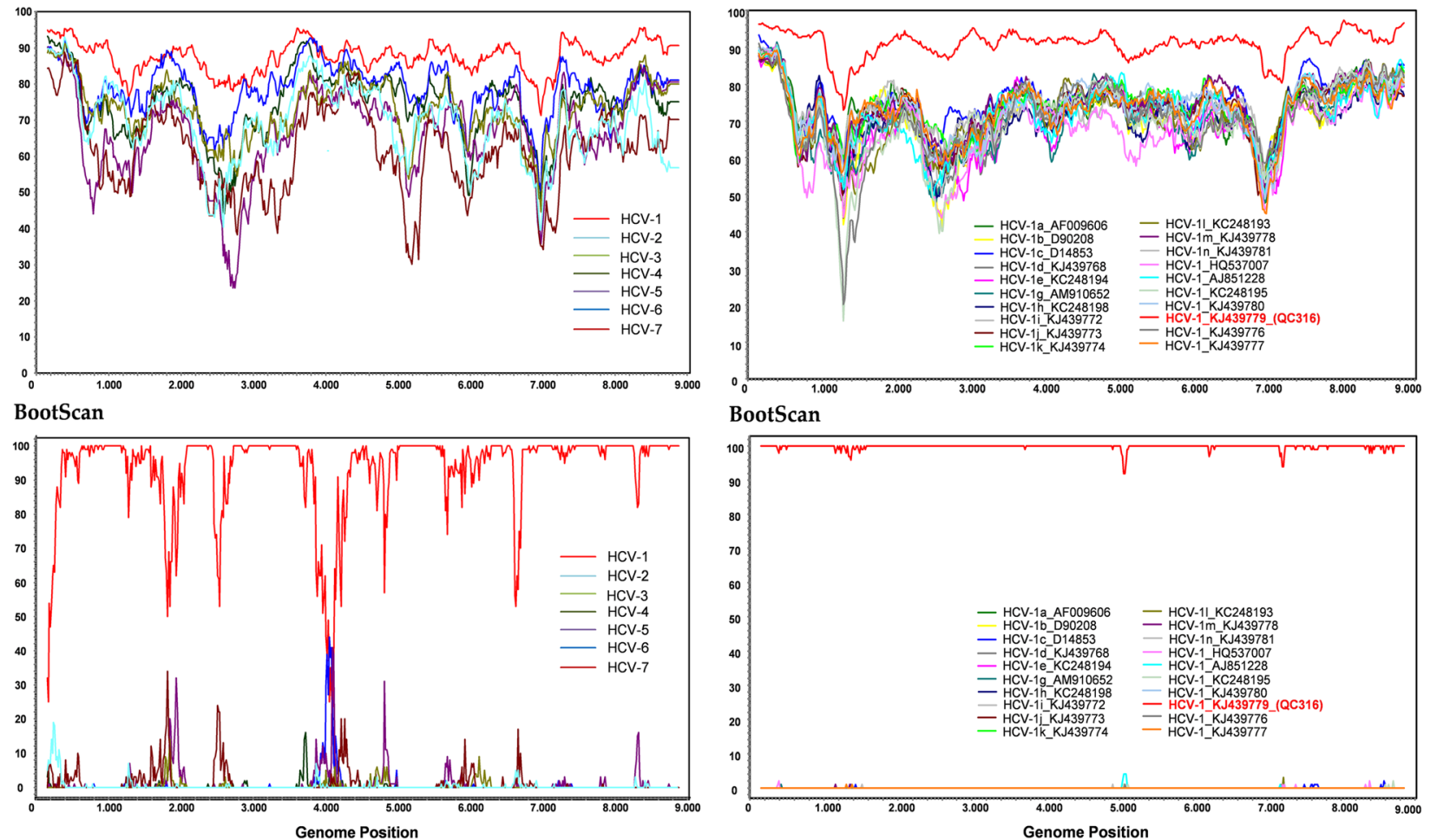

Fig. 2 Analysis of potential recombination events of the DE/17-0414. Identity Plot and BootScan analyses of (a) HCV genotypes and (b) HCV-1 subtypes. All analyses were performed with a window of $300 \mathrm{nt}$ and a step size of $15 \mathrm{nt}$ under Kimura 2-parameter model. Positions containing gaps were stripped from the alignment. QC316 is highlighted in bold and red

glycoproteins 1 and 2 constitute the structural elements of HCV [20]. The N-terminal of E2, called HVR1, is most divergent among $\mathrm{HCV}$ isolates and contributes to immune escape [21]. A distinct 3 aa (Q-S-R) insertion at the N-terminal of HVR1 was found in DE/17-0414 which exists in none of other known $\mathrm{HCV}$ strains. Whether the insertion is associated to HIV-coinfection and its function needs to be further analyzed. With the approval of DAA regimens testing $\mathrm{HCV}$ for RASs is clinically relevant. Several potential RASs were detected in the NS3 and NS5A genomic regions of DE/17-0414 on the basis of HCV subtypes $1 \mathrm{a}$ and $1 \mathrm{~b}$ [6], indicating that corresponding DAAs should be avoided in this individual.

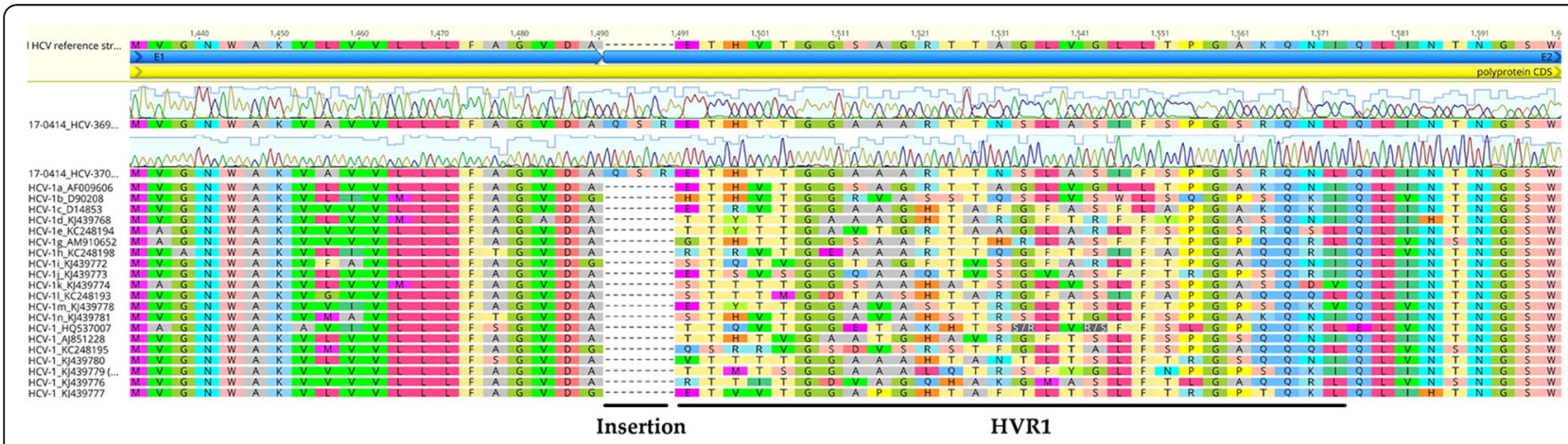

Fig. 3 Sequence alignment of HCV-1 E1 and E2 genomic regions. The newly detected Q-S-R insertion of DE/17-0414 and HVR1 at the N-terminal of E2 is indicated at the bottom. Absolute numbering is corresponding to aa position 364 to 420 of $\mathrm{H} 77$ reference strain 
Table 3 Insertion and potential direct-acting antivirals resistance-associated substitutions of DE/-17-0414

\begin{tabular}{|c|c|c|c|c|}
\hline $\begin{array}{l}\text { Genomic } \\
\text { regions }\end{array}$ & $\begin{array}{l}\text { Amino acid } \\
\text { position }\end{array}$ & $\begin{array}{l}\text { Reference } \\
\text { amino acid }\end{array}$ & $\mathrm{DE} /-17-0414$ & $\begin{array}{l}\text { Susceptibility to DAA according to } \\
\text { Geno2Pheno[HCV] (Kalaghatgi et al., 2016) }\end{array}$ \\
\hline E2 & $1 a-1 c$ & - & QSR & $N A^{a}$ \\
\hline NS3 & 36 & V & L & $\begin{array}{l}\text { Substitution on scored position to Asunaprevir, Grazoprevir, Ledipasvir, } \\
\text { Paritaprevir; Reduced susceptibility to Simeprevir, Telaprevir, } \\
\text { Voxilaprevir; Resistant to Boceprevir }\end{array}$ \\
\hline NS3 & 170 & I & V & Substitution on scored position to Voxilaprevir \\
\hline NS5A & 28 & $L$ & M & Substitution on scored position to Ombitasvir \\
\hline NS5A & 31 & $\mathrm{~L}$ & M & Substitution on scored position to Velpatasvir \\
\hline NS5A & 93 & Y & $\mathrm{H}$ & $\begin{array}{l}\text { Substitution on scored position to Pibrentasvir; } \\
\text { Resistant to Daclatasvir, Elbasvir, Ledipasvir, Ombitasvir, Velpatasvir }\end{array}$ \\
\hline
\end{tabular}

${ }^{a}$ NA for not available

In conclusion, we identified and analyzed an HCV-1 divergent isolate from an HIV-1 coinfected individual in Germany, which will be assigned to a new subtype 1o with other three epidemiologically unrelated analogous $\mathrm{HCV}$ isolates. The origin and transmission dynamics of this new subtype needs further verification by more comprehensive genetic analyses of HCV strains from patients worldwide.

\section{Abbreviations}

aa: Amino acid; DAAs: direct-acting antivirals; DSS: Dried serum spot; E2: envelope glycoprotein 2; HCV: Hepatitis C virus; HCV-1: Hepatitis C virus genotype 1; HIV-1: Human immunodeficiency virus type 1;

HVR1: Hypervariable region 1; ICTV: International committee on taxonomy of viruses; nt: Nucleotide; RASs: Resistance-associated substitutions; RKI: Robert koch institute; WHO: World health organization

\section{Acknowledgements}

We are grateful for the excellent technical assistance of Marcel Schulze, Julian Heinze, Ewelina Caspers, Steffen Zander, and Hanno von Spreckelsen (RKI).

\section{Funding}

This work was supported by a grant from the German Federal Ministry of Health (BMG, grant: ZMVI1-2516-AUK-701 / BMG: 321-4471-02/157). B.W. is funded by the China Scholarship Council (CSC), Beijing, China. A.E. is funded by a scholarship from the German Academic Exchange Service (DAAD), Bonn, Germany. The content is the responsibility only of the authors and does not represent the views of the BMG, CSC or DAAD.

\section{Availability of data and materials}

All data generated or analysed during this study are included in this published article.

\section{Authors' contributions}

NB and CTB conceptualized the study. BW, LK, PM, AE performed the experiment and data analysis. $\mathrm{AE}, \mathrm{AH}$, and PM collected specimens. BW, PM, and $\mathrm{AH}$ drafted the manuscript. NB, BGB, VB and CTB revised the manuscript critically. All authors read and approved the final manuscript.

\section{Ethics approval and consent to participate}

Not applicable. According to IfSG $\$ 13$ (2017), the RKI is authorized to receive anonymous blood residuals from diagnostics laboratories for surveillance purposes. The KOKPIT study has been approved by the data protection officer of the RKI.

\section{Consent for publication}

Not applicable.

\section{Competing interests}

The authors declare no conflict of interest. The funders had no role in the design of the study; in the collection, analyses, or interpretation of data; in the writing of the manuscript, and in the decision to publish the results.

\section{Publisher's Note}

Springer Nature remains neutral with regard to jurisdictional claims in published maps and institutional affiliations.

\section{Author details}

'Division of Viral Gastroenteritis, Hepatitis Pathogens and Enteroviruses, Department of Infectious Diseases, Robert Koch Institute, 13353 Berlin, Germany. ${ }^{2}$ Division of HIV and other Retroviruses, Department of Infectious Diseases, Robert Koch Institute, 13353 Berlin, Germany. ${ }^{3}$ Division of HIV/AIDS, STI and Blood-borne Infections, Department of Infectious Diseases Epidemiology, Robert Koch Institute, 13353 Berlin, Germany. Institute of Medical Virology, Charité - Universitätsmedizin Berlin, 10117 Berlin, Germany. ${ }^{5}$ Institute of Tropical Medicine, University of Tübingen, 72076 Tübingen, Germany.

Received: 8 November 2018 Accepted: 22 February 2019 Published online: 04 March 2019

\section{References}

1. WHO: Hepatitis C Fact Sheet. Available online: http://www.who.int/newsroom/fact-sheets/detail/hepatitis-c (accessed 22 October 2018).

2. Operskalski EA, Kovacs A. HIV/HCV co-infection: pathogenesis, clinical complications, treatment, and new therapeutic technologies. Curr HIV/AIDS Rep. 2011;8(1):12-22.

3. Neukam K, Morano-Amado LE, Rivero-Juarez A, Mancebo M, Granados R, Tellez F, Collado A, Rios MJ, de Los Santos-Gil I, Reus-Banuls S, et al. HIVcoinfected patients respond worse to direct-acting antiviral-based therapy against chronic hepatitis $\mathrm{C}$ in real life than HCV-monoinfected individuals: a prospective cohort study. HIV Clin Trials. 2017;18(3):126-34.

4. Schlabe S, Rockstroh JK. Advances in the treatment of HIV/HCV coinfection in adults. Expert Opin Pharmacother. 2018;19(1):49-64.

5. Sarrazin C. The importance of resistance to direct antiviral drugs in HCV infection in clinical practice. J Hepatol. 2016;64(2):486-504.

6. Pawlotsky JM. Hepatitis $C$ virus resistance to direct-acting antiviral drugs in interferon-free regimens. Gastroenterology. 2016;151(1):70-86.

7. Simmonds P, Becher P, Bukh J, Gould EA, Meyers G, Monath T, Muerhoff S, Pletnev A, Rico-Hesse R, Smith DB, et al. ICTV virus taxonomy profile: Flaviviridae. J Gen Virol. 2017:98(1):2-3.

8. Smith DB, Bukh J, Kuiken C, Muerhoff AS, Rice CM, Stapleton JT, Simmonds P. Expanded classification of hepatitis C virus into 7 genotypes and 67 subtypes: updated criteria and genotype assignment web resource. Hepatology. 2014;59(1):318-27.

9. Messina JP, Humphreys I, Flaxman A, Brown A, Cooke GS, Pybus OG, Barnes E. Global distribution and prevalence of hepatitis $C$ virus genotypes. Hepatology. 2015;61(1):77-87.

10. Kartashev V, Doring M, Nieto L, Coletta E, Kaiser R, Sierra S, Group HCVES. New findings in HCV genotype distribution in selected west European, Russian and Israeli regions. J Clin Virol. 2016;81:82-9.

11. Hauser A, Hofmann A, Hanke K, Bremer V, Bartmeyer B, Kuecherer C Bannert N: National molecular surveillance of recently acquired HIV infections in Germany, 2013 to 2014. Euro Surveill 2017, 22(2), pii: 30436. 
12. Wang B, Yang XL, Li W, Zhu Y, Ge XY, Zhang LB, Zhang YZ, Bock CT, Shi ZL. Detection and genome characterization of four novel bat hepadnaviruses and a hepevirus in China. Virol J. 2017;14(1):40.

13. Kumar S, Stecher G, Tamura K. MEGA7: molecular evolutionary genetics analysis version 7.0 for bigger datasets. Mol Biol Evol. 2016;33(7):1870-4.

14. Lole KS, Bollinger RC, Paranjape RS, Gadkari D, Kulkarni SS, Novak NG, Ingersoll R, Sheppard HW, Ray SC. Full-length human immunodeficiency virus type 1 genomes from subtype $C$-infected seroconverters in India, with evidence of intersubtype recombination. J Virol. 1999;73(1):152-60.

15. Kalaghatgi P, Sikorski AM, Knops E, Rupp D, Sierra S, Heger E, NeumannFraune M, Beggel B, Walker A, Timm J, et al. Geno2pheno[HCV] - a webbased interpretation system to support hepatitis $C$ treatment decisions in the era of direct-acting antiviral agents. PLoS One. 2016;11(5):e0155869.

16. Kuiken C, Combet C, Bukh J, Shin IT, Deleage G, Mizokami M, Richardson R, Sablon E, Yusim K, Pawlotsky JM, et al. A comprehensive system for consistent numbering of HCV sequences, proteins and epitopes. Hepatology. 2006:44(5):1355-61.

17. Lu L, Li C, Xu Y, Murphy DG. Full-length genomes of 16 hepatitis $C$ virus genotype 1 isolates representing subtypes $1 \mathrm{c}, 1 \mathrm{~d}, 1 \mathrm{e}, 1 \mathrm{~g}, 1 \mathrm{~h}, 1 \mathrm{i}, 1 \mathrm{j}$ and $1 \mathrm{k}$ and two new subtypes $1 \mathrm{~m}$ and $1 \mathrm{n}$, and four unclassified variants reveal ancestral relationships among subtypes. J Gen Virol. 2014;95(7):1479-87.

18. Koletzki D, Dumont S, Vermeiren H, Fevery B, De Smet P, Stuyver LJ. Development and evaluation of an automated hepatitis C virus NS5B sequence-based subtyping assay. Clin Chem Lab Med. 2010:48(8):1095-102.

19. Schroter M, Zollner B, Schafer P, Reimer A, Muller M, Laufs R, Feucht HH. Epidemiological dynamics of hepatitis $C$ virus among 747 German individuals: new subtypes on the advance. J Clin Microbiol. 2002;40(5):1866-8.

20. Penin F, Dubuisson J, Rey FA, Moradpour D, Pawlotsky JM. Structural biology of hepatitis C virus. Hepatology. 2004;39(1):5-19.

21. Bankwitz D, Vieyres G, Hueging K, Bitzegeio J, Doepke M, Chhatwal P, Haid $\mathrm{S}$, Catanese MT, Zeisel MB, Nicosia A, et al. Role of hypervariable region 1 for the interplay of hepatitis C virus with entry factors and lipoproteins. J Virol. 2014;88(21):12644-55.

Ready to submit your research? Choose BMC and benefit from:

- fast, convenient online submission

- thorough peer review by experienced researchers in your field

- rapid publication on acceptance

- support for research data, including large and complex data types

- gold Open Access which fosters wider collaboration and increased citations

- maximum visibility for your research: over $100 \mathrm{M}$ website views per year

At $\mathrm{BMC}$, research is always in progress.

Learn more biomedcentral.com/submissions 